ORIGINAL ARTICLE

\title{
The clinical and health economic burden of respiratory syncytial virus disease among children under 2 years of age in a defined geographical area
}

\author{
S A Deshpande, V Northern
}

Arch Dis Child 2003;88:1065-1069

See end of article for authors' affiliations

Correspondence to

Correspondence to:
Dr S A Deshpande, Royal

Shrewsbury Hospital,

Mytton Oak Road,

Shrewsbury SY3 8XQ, UK;

deshpande@which.net

Accepted 17 April 2003

\begin{abstract}
Aims: To describe the clinical and health economic impact of respiratory syncytial virus (RSV) disease in children under 2 years of age.

Methods: Hospitalised children less than 2 years of age with a respiratory illness were studied over three consecutive RSV seasons (1996-99).

Results: The rates (per 1000 infants under 1 year of age) of hospitalisations from bronchiolitis and RSV illness were 30.8 and 24.4 respectively. The rates of death, intensive care admission, and need for ventilatory assistance during RSV related hospitalisation were $0.2 \%, 2.7 \%$, and $1.5 \%$ respectively. From a cohort of 841 preterm infants, $6.3 \%$ had an RSV related hospitalisation during the study period, with the rate rising to $9.2 \%$ among those who were either born before 36 weeks gestation and were under 6 months of age at the onset of the RSV seasons, or were less than 2 years of age with chronic lung disease needing home oxygen therapy. Eight of 25 children on home oxygen therapy had RSV related rehospitalisation. Need for assisted ventilation during the neonatal period and discharge home on oxygen therapy were significantly associated with the risk of subsequent RSV related hospitalisation in preterm infants less than 6 months of age. The direct health authority cost of all RSV hospitalisations was £542 203, while the currently recommended immunoprophylaxis for the high risk infants would have cost £652 960 . Conclusions: Preterm infants receiving assisted ventilation and those on home oxygen therapy are particularly at risk of RSV related hospitalisation. Serious adverse outcomes are however uncommon even among these high risk infants.
\end{abstract}

$\mathrm{R}$ espiratory syncytial virus (RSV) is a major cause of lower respiratory tract disease in young children. ${ }^{1}$ For over four decades, attempts have been made to prevent RSV disease, both through active and passive immunisations. Recently, a humanised monoclonal antibody (palivizumab) showed a 55\% reduction in RSV associated hospitalisation rates among "high risk" infants (preterm and those with chronic lung disease). ${ }^{2}$ The product is however expensive, and the cost effectiveness of administering it to the recommended groups of infants has been challenged. ${ }^{34}$

In order to identify the infants at the greatest benefit from such immunoprophylaxis, recent studies have focused on the incidence of RSV disease in the high risk population..$^{5-7}$ Epidemiological studies of bronchiolitis and RSV disease across both "low" and "high" risk infants are, however, limited with the last UK data being over 25 years old ${ }^{89}$ Reliable population based data on the clinical and health economic burden of RSV in both the "low" and "high" risk children are urgently needed to assess the cost effectiveness of newer preventive therapies in the context of the total burden of the disease.

The objectives of our study were: (1) to define the clinical (need for, and duration of hospitalisation, intensive care admission and mechanical ventilation, and mortality) and health economic (health authority costs) impact of RSV disease among children less than 2 years of age resident in a geographically defined population; (2) to define the contribution of RSV to respiratory hospitalisations in children under 2 years; and (3) to determine the incidence and predictors of, RSV related hospitalisations among the "high risk" infants

\section{METHODS}

Denominator population

Shropshire is predominantly rural; $55.1 \%$ of its population $(n=433650)$ resides in areas with less than 25 people per hectare. The county's Child Health System database was interrogated to provide the population of all children under 2 years of age resident within Shropshire Health Authority (SHA) as on 1 November 1996, 1997, and 1998. This cohort excluded children who were born in SHA but had moved out of the county prior to the onset of RSV season, but included those born elsewhere who had moved into SHA before the RSV season.

\section{High risk population}

Preterm infants ( $<37$ weeks gestation) under 1 year of age, and children under 2 years of age with chronic lung disease (CLD; oxygen dependency at 36 weeks post-menstrual age) discharged on home oxygen therapy or respiratory medications (bronchodilators, diuretics, and oral or inhaled steroids) in whom there was continuing involvement of the neonatal home oxygen service within six months of the start of the RSV season constituted the "high risk" group. We excluded children with congenital heart disease other than a patent arterial duct in preterm infants, as the immunoprophylaxis is currently not indicated for such children. ${ }^{10}$ We extracted details of the neonatal period, including gestational age and birth weight, need for and duration of assisted ventilation, need for supplemental oxygen at 4 weeks of postnatal and 36 weeks of postmenstrual age, date and details of medications at discharge from the neonatal unit, and need for home oxygen therapy from the neonatal records.

Abbreviations: CLD, chronic lung disease; FCE, finished consultant episode; LRTI, lower respiratory tract infection; RSV, respiratory syncytial virus 


\section{Children with RSV disease}

The Shropshire-wide single microbiology database was interrogated to provide a cohort of children under 2 years of age with a positive RSV immunofluorescence test between 1 April 1996 and 31 March 1999. By linkage of this cohort to the SHA's database, we excluded children not ordinarily resident within the SHA. We ascertained the RSV status and details of hospitalisation of Shropshire resident children admitted with bronchiolitis or other lower respiratory tract illnesses (LRTI) to hospitals outside the county by contacting the local paediatricians.

\section{Hospitalisation}

The health authority's database provided details of hospitalisation of all Shropshire resident children less than 2 years of age, irrespective of the place of their hospitalisation.

A bronchiolitis associated hospitalisation was defined as any hospitalisation where International Classification of Diseases, 10th revision (ICD-10) Codes $^{11}$ for acute bronchiolitis (J21.0, 21.8, and 21.9) appeared anywhere in the discharge coding.

An $R S V$ related hospitalisation was defined as a hospitalisation with positive RSV immunofluorescence test within seven days of admission. This strategy included all respiratory illnesses associated with RSV such as bronchiolitis, pneumonia, and croup.

Hospitalisation due to other LRTI was defined by ICD-10 codes J10-18 and J20-22 in the diagnostic coding. This strategy excluded hospitalisations due to asthma.

For these hospitalisations, we analysed the length of hospital stay, the need for intensive care unit (ICU) admission and ventilatory support, and deaths, from the aforementioned databases as well as clinical records. For calculation of rates of hospitalisation, we assigned infants born between 1 November of the given year and 31 October of the subsequent year to the season starting on 1 November of the latter year.

We used the SHA's contract price for an emergency finished consultant episode (FCE) for the three study years to calculate the hospitalisation costs. For children admitted to the ICU, the price quoted by the relevant unit was used.

Mann-Whitney U test and the $\chi^{2}$ test with Fisher's exact modification where necessary, were used for comparison of the continuous variables and the proportions, respectively. The associations between a number of predictor variables and the occurrence of hospitalisations were analysed by the $\chi^{2}$ test. Predictor variables that were significant at $\mathrm{p}<0.05$ in the bivariate analyses were entered into a multiple logistic regression model to assess their influence on the risk of RSV related hospitalisation among the high risk infants.

\section{RESULTS}

Of 15116 infants under 1 year of age resident in the county at the start of the three RSV seasons, 452 (3\%) had moved in some time after birth. Details of gestation and birth weight were unavailable for $82.2 \%$ and $20 \%$ of this latter group. On the other hand, this information was available for $99.8 \%$ and $100 \%$ of Shropshire resident infants who were either born in the county or had transferred into it, at or soon after birth, and hence the gestation and birth weight specific rates of hospitalisation were calculated for these infants $(n=14664)$. Of the 452 excluded infants, six were known to be preterm and 15 weighed under $2500 \mathrm{~g}$ at birth. There were 24 bronchiolitis associated and 11 RSV related hospitalisations among these infants.

\section{Bronchiolitis associated hospitalisations}

There were 653 bronchiolitis associated hospitalisations among 561 children $<2$ years $(21.4$ hospitalisations/1000 children). Bronchiolitis was the primary diagnosis in $94.9 \%$ of these hospitalisations. RSV status was known in $77 \%$, and positive in $58.8 \%$ of these hospitalisations. The majority of admissions (93.8\%) occurred between months of November and March each year. Forty three $(6.6 \%)$ hospitalisations took place in hospitals outside the county. During the study period, bronchiolitis accounted for $7.7 \%$ of all-cause hospitalisations among children $<2$ years of age.

The median (interquartile range) age at hospitalisation was 20 (10-33) weeks, with infants less than 12 and 6 months of age accounting for $92.8 \%$ and $63.9 \%$ of hospitalisations, respectively (table 1 ). These hospitalisations resulted in 1616 in-patient days with a median (interquartile range) length of stay of $2(1-3)$ days. Ninety eight (16.2\%) admissions took place among preterm infants.

During the same period, there were 446 hospitalisations among 399 children under 2 years from other lower respiratory tract infection (LRTI). Pneumonia (41\%) and unspecified LRTI $(46 \%)$ were the most common primary diagnoses. Compared to bronchiolitis associated hospitalisations, this cohort was older and did not show any specific seasonal variation (table 2 ). Bronchiolitis associated hospitalisations accounted for $76 \%$ of the hospitalisations of infants under 6 months from all LRTI, rising to $86 \%$ during the months of November to April.

\section{RSV related hospitalisation}

During the study period, there were 497 RSV related hospitalisations (386 coded as bronchiolitis) in 411 children under 2 years (16.3 hospitalisations/1000 children). Eighty three per cent had one, $15 \%$ had two, and $2 \%$ had three hospitalisations. Boys predominated over girls in the ratio of 1.5:1. The vast majority (98.9\%) of hospitalisations occurred between November and March each year. RSV infections accounted for $9.8 \%$ of all pneumonias in children less than 2 years of age, with the proportion increasing to $25 \%$ of infants under 1 year during the RSV season.

The median (interquartile range) age at hospitalisation was 20.5 (10.4-35.3) weeks, with $62 \%$ and $90 \%$ of the children being under 6 and 12 months of age, respectively. Forty five infants were under 6 weeks of age and 67 (16.7\% of those with known gestation) were preterm. The subgroup specific rates of hospitalisations are shown in table 1 . The median (range) length of RSV related hospitalisation was 2 (0-19) days. Hospital stays were significantly longer in infants less than 6 weeks of age at admission (median (interquartile range): $4(2-5) \vee 2(1-4)$ days; $p=0.008)$, and those with birth weight under $2500 \mathrm{~g}$ (median (interquartile range): 4 $(2-5) \vee 2(1-4)$ days; $\mathrm{p}=0.032$ ).

Table 1 Rates of bronchiolitis associated and RSV related hospitalisations (per 100 children born in or moved in soon after birth and resident in the county on 1 November of the relevant year)

\begin{tabular}{|c|c|c|c|}
\hline & Number & $\begin{array}{l}\text { Bronchiolitis } \\
\text { associated } \\
\text { hospitalisations }\end{array}$ & $\begin{array}{l}\text { RSV related } \\
\text { hospitalisations }\end{array}$ \\
\hline Infants $<1$ year of age & 14664 & 3.1 & 2.4 \\
\hline Boys $<1$ year of age & 7513 & 3.5 & 2.7 \\
\hline Infants $<6$ months of age & 7534 & 4.6 & 3.6 \\
\hline Boys $<6$ months of age & 3851 & 4.1 & 3.8 \\
\hline \multicolumn{4}{|l|}{$\begin{array}{l}\text { Infants under } 6 \text { months of } \\
\text { age }\end{array}$} \\
\hline$\leqslant 36$ weeks gestation & 496 & 11.3 & 8.9 \\
\hline$\leqslant 32$ weeks gestation & 135 & 14.1 & 8.9 \\
\hline$\leqslant 28$ weeks gestation & 32 & 12.5 & 12.5 \\
\hline Birth weight $<2500 \mathrm{~g}$ & 503 & 11.5 & 8.5 \\
\hline Birth weight $<1500 \mathrm{~g}$ & 89 & 15.7 & 7.9 \\
\hline Birth weight $<1000 \mathrm{~g}$ & 33 & 21.2 & 9.1 \\
\hline
\end{tabular}


Table 2 Characteristics of hospitalisations due to bronchiolitis and other lower respiratory tract illnesses (LRTI), excluding asthma among children under 2 years of age, 1996-99

\begin{tabular}{lll}
\hline & $\begin{array}{l}\text { Bronchiolitis } \\
\text { associated } \\
\text { hospitalisations }\end{array}$ & $\begin{array}{l}\text { Hospitalisations } \\
\text { due to other LRTI }\end{array}$ \\
\hline Number & 653 & 446 \\
Age at hospitalisation (weeks)* & $20(10-33)$ & $51(25-73)$ \\
Age $<1$ year $(\%)^{*}$ & 92.8 & 50.5 \\
Age $<6$ months (\%) & 63.9 & 26 \\
Boys (\%) & 56.7 & 62 \\
$\begin{array}{l}\text { Preterm (\%) } \\
\text { Birth weight }<2500 \mathrm{~g}(\%)\end{array}$ & 15.2 & 16.7 \\
$\begin{array}{l}\text { Admission between November } \\
\text { and April (\%)* }\end{array}$ & 17.1 & 14.1 \\
Median (interquartile) duration \\
of hospitalisation (days)
\end{tabular}

\section{High risk infants}

Of the study cohort of infants, $6.3 \%$ and $1.1 \%$ were born before 37 and 32 weeks of gestation, respectively. Complete neonatal data were available for 846 preterm infants. This cohort comprised $88.5 \%, 93 \%$, and $100 \%$ of surviving infants born before 37,36 , and 28 weeks of gestation respectively, and resident in the county at the start of the RSV season. Five infants with congenital heart disease were excluded from further analysis. Of 209 infants of $\leqslant 32$ weeks gestation who had received active respiratory support, 33\% developed CLD. The incidence of home oxygen therapy among the survivors of $<32$ weeks gestation with oxygen dependency at 28 days of age, and among the survivors of 501-1500 g birth weight was $29 \%$ and $10.6 \%$, respectively. Of Shropshire's live born infants between 1995 and 1998, 105 (5.2/1000) were reported to the regional congenital abnormalities register with structural congenital heart disease.

\section{Preterm infants}

Fifty three preterm infants for whom complete neonatal data were available $(6.3 \%)$ had an RSV related hospitalisation during the study period, resulting in 249 in-patient days. The median (interquartile range) age at, and duration of, hospitalisation were 23.7 (11.6-38.3) weeks and 2 (1-4) days, respectively.

Of 436 preterm infants under 6 months, 6.9\% had an RSV related hospitalisation during the relevant season. Table 3 shows the risk factors for RSV related hospitalisation among these infants. In the logistic regression model, ventilatory assistance during neonatal period (OR (95\% CI) 2.8 ( 1.2 to 6.3 )) and discharge home on oxygen (OR (95\% CI) 5.5 ( 1.1 to 24.5)) were significantly associated with the risk of subsequent RSV related hospitalisation. Gestation and weight at birth, month of discharge from the neonatal unit, and occurrence of intracranial bleeds or retinopathy (data not shown) did not influence the risk of RSV related admission.

Of 304 infants who were either $<36$ weeks of gestation and $<6$ months of age at the start of the RSV season, or $<2$ years of age and were discharged on home oxygen therapy, $28(9.2 \%)$ were rehospitalised for RSV disease. Of 136 babies born before 32 weeks gestation, 10.3\% had an RSV related rehospitalisation before their second birthday. Ten of 110 infants born before 32 weeks of gestation who were either under 6 months at the start of the RSV seasons $(n=85)$ or under 2 years with the last involvement of neonatal home oxygen service within 6 months of the impending RSV season $(n=25)$, were rehospitalised for RSV during the relevant season. Six of $58(10.3 \%)$ infants born $<29$ weeks of gestation
Table 3 Risk factors for RSV related hospitalisation among preterm ( $\leqslant 36$ weeks gestation) infants under 6 months of age at the onset of each RSV season (1 November) 1996-99

\begin{tabular}{|c|c|c|}
\hline & $\mathbf{n}$ & $\begin{array}{l}\text { RSV related } \\
\text { hospitalisation, } \\
\text { n (\%) }\end{array}$ \\
\hline Overall & 436 & $30(6.9)$ \\
\hline \multicolumn{3}{|l|}{ Gestation } \\
\hline $24-32$ weeks & 120 & 9 \\
\hline $33-36$ weeks & 316 & 21 \\
\hline \multicolumn{3}{|l|}{ Birth weight } \\
\hline$\leqslant 1500 \mathrm{~g}$ & 83 & 6 \\
\hline$>1500 \mathrm{~g}$ & 353 & 24 \\
\hline \multicolumn{3}{|l|}{ Sex } \\
\hline Male & 229 & $13(5.7)$ \\
\hline Female & 207 & $17(8.3)$ \\
\hline \multicolumn{3}{|l|}{ Multiple gestation } \\
\hline Singleton & 355 & $23(6.5)$ \\
\hline Multiple & 81 & $7(8.6)$ \\
\hline \multicolumn{3}{|l|}{ Assisted ventilation* } \\
\hline Yes & 111 & $14(12.6)$ \\
\hline No & 325 & $16(4.9)$ \\
\hline \multicolumn{3}{|l|}{ Oxygen therapy } \\
\hline$\geqslant 28$ days & 43 & $4(9.5)$ \\
\hline$<28$ days & 393 & $26(6.6)$ \\
\hline \multicolumn{3}{|c|}{$\begin{array}{l}\text { Oxygen dependency at } 36 \text { weeks of } \\
\text { post-menstrual age }{ }^{*}\end{array}$} \\
\hline Yes & 28 & $3(10.7)$ \\
\hline No & 408 & $27(6.6)$ \\
\hline \multicolumn{3}{|c|}{ Steroids for chronic lung disease* } \\
\hline Yes & 34 & $3(9.1)$ \\
\hline No & 402 & $27(6.7)$ \\
\hline \multicolumn{3}{|c|}{ Home oxygen therapy* } \\
\hline Yes & 11 & $3(27.3)$ \\
\hline No & 425 & $27(6.4)$ \\
\hline \multicolumn{3}{|c|}{ Discharge from neonatal unit } \\
\hline May-October & 388 & $27(7.0)$ \\
\hline November-April & 48 & $3(6.4)$ \\
\hline
\end{tabular}

had an RSV related hospitalisation during their first year; one further infant was admitted before the second birthday.

\section{Preterm infants with CLD under 2 years of age}

Ten of $64(15.6 \%)$ preterm infants with CLD had an RSV related hospitalisation before their second birthday, accounting for a total of 50 in-patient days. The median (interquartile range) age at, and duration of hospital stay were 53 (33-84) weeks and 3.5 (2-9) days respectively. Eight of the 25 children under 2 years with CLD on home oxygen therapy had RSV related rehospitalisations.

\section{Serious adverse outcomes of RSV related hospitalisation}

One infant $(0.2 \%)$ with complex congenital heart disease died from an RSV related illness during the study period. Eleven children $(2.7 \%)$, six preterm, were admitted to the intensive care unit; six (1.5\%) infants, three preterm, required ventilatory assistance for a total of 27 days.

\section{The health economic costs}

The maximum costs incurred by the health authority over the three year period for bronchiolitis associated and RSV related hospitalisations of all children under 2 years of age were $£ 542203$ and £421 938 respectively, with preterm infants $<36$ weeks gestation under 6 months of age accounting for $13.7 \%$ and $11 \%$ of these costs respectively. RSV rehospitalisations (including ICU admissions) of children under 2 years of age with CLD contributed to $8.1 \%$ of total RSV related health authority costs. Table 4 shows the minimum costs of prophylaxis with palivizumab for various "at risk" groups of infants. 


\begin{tabular}{|c|c|c|c|}
\hline $\begin{array}{l}\text { Source of } \\
\text { recommendations }\end{array}$ & Criteria for prophylaxis: infants who are... & $\begin{array}{l}\text { Number } \\
\text { eligible }\end{array}$ & $\begin{array}{l}\text { Cost of } \\
\text { prophylaxis }(£)^{*}\end{array}$ \\
\hline |Mpact-RSV trial $^{2}$ & $\begin{array}{l}\text { (i) }<6 \text { months of age and born } \leqslant 35 \text { weeks } \\
\text { gestation } \\
\text { (ii) }<2 \text { years of age with chronic lung disease on } \\
\text { home oxygen/respiratory medications within } \\
6 \text { months }\end{array}$ & 308 & $652960+$ \\
\hline $\begin{array}{l}\text { American Academy } \\
\text { of Paediatrics }\end{array}$ & $\begin{array}{l}\text { (i) }<2 \text { years of age with chronic lung disease on } \\
\text { home oxygen/respiratory medications within } \\
6 \text { months } \\
\text { (ii) born } \leqslant 28 \text { weeks gestation, not meeting } \\
\text { criterion (i) up to } 12 \text { months of age } \\
\text { (iii) born at } 29-32 \text { weeks gestation, not meeting } \\
\text { criterion (i) up to } 6 \text { months of age }\end{array}$ & 147 & $311640 \dagger$ \\
\hline Joffe et $a^{5}$ & $\begin{array}{l}\text { Gestation } \leqslant 32 \text { weeks and oxygen requirement } \\
>28 \text { days and discharge from NICU during the } \\
3 \text { months before the RSV season }\end{array}$ & 24 & $84720 \ddagger$ \\
\hline Thomas et $a l^{\beta}$ & $\begin{array}{l}<2 \text { years of age with chronic lung disease on } \\
\text { home oxygen/respiratory medications within } \\
6 \text { months }\end{array}$ & 25 & $88250 \ddagger$ \\
\hline
\end{tabular}

*Price of palvizumab: $50 \mathrm{mg}$ vial, £424; $100 \mathrm{mg}$ vial, £706.

†Assuming all infants weighed $<3.3 \mathrm{~kg}$ at prophylaxis.

$\ddagger$ Assuming all infants weighed $>3.3 \mathrm{~kg}$ at prophylaxis.

\section{DISCUSSION}

Our study provides the epidemiological features of RSV disease among all infants in a defined geographic population. The salient findings of our study are that: (1) the rates of RSV related hospitalisations in infancy have tripled in the past 25 years; (2) preterm infants requiring ventilatory assistance during the neonatal period, and those discharged on home oxygen therapy are at particular risk of RSV related hospitalisation; and (3) serious adverse outcomes are rare, even among the high risk infants.

\section{Strengths and limitations}

We took several measures to minimise potential biases. Our use of the health authority's database ensured inclusion of all admissions of Shropshire resident children from bronchiolitis irrespective of their place of hospitalisation. Our strategy of defining the cohort of children with bronchiolitis by using the occurrence of the relevant diagnostic codes anywhere in the diagnostic coding ensured inclusion of children with complicated illness such as respiratory failure or nosocomially acquired illness. Inappropriate coding may have influenced the incidence of bronchiolitis. However, with its characteristic clinical picture and well defined seasonal incidence, clinical diagnosis of bronchiolitis is reliable. These codes were used in only $3.7 \%$ of hospitalisations outside the usual RSV season. Furthermore, a local audit of the accuracy of coding confirmed that $95 \%$ of cases of clinically diagnosed bronchiolitis were correctly coded. The incidence of RSV related hospitalisations might have been underestimated if there was a higher proportion of RSV positivity among the RSV unknown hospitalisations. The proportion of RSV known bronchiolitis in our cohort (77\%) was, however, higher than has been reported from the UK in recent years. ${ }^{6}$ We excluded outborn infants who had transferred into the county due to non-availability of gestational age data. As the rates of hospitalisations in this group were similar to the study cohort, their exclusion is unlikely to be of significance.

Shropshire has lower population density and deprivation than the average for England. However, the rates of prematurity, congenital heart disease, CLD, and home oxygen therapy, the risk factors for severe RSV disease, in our cohort compare well with the published population based data from the UK and North America. ${ }^{12-16}$

\section{Other studies}

Bronchiolitis related hospitalisations

The rate of bronchiolitis related hospitalisation among infants under 1 year of age in our study $(3.1 \%)$ is the same as that derived from US National Hospital Discharge Survey data (3.1\%). ${ }^{17}$ No comparable UK data exist.

The rate of RSV related hospitalisation in infancy in our study $(2.4 \%)$ was nearly three times that in a previous collaborative investigation of RSV infection across the UK in 1973-75. . For a predominantly rural county, it is also higher than that previously reported from northeast England over 25 years ago. ${ }^{18} \mathrm{~A}$ similar increase in the rates of bronchiolitis associated hospitalisations has been seen in US children from 1980 to $1996 .{ }^{17}$ The rise was particularly marked for infants under 6 months, suggesting either increased acquisition of RSV or a lower threshold for admission in this group of infants. Other factors including improved survival of premature infants, increased population density, altered child care practices, and increasing use of pulse oximetry to detect hypoxia may underlie this substantial increase in RSV related hospitalisations.

\section{High risk infants}

Our data show that high risk infants contribute a small proportion of total clinical burden of bronchiolitis and RSV disease. Preterm infants and infants with CLD accounted for $16.6 \%$ and $1.9 \%$ of RSV related hospitalisations. In the US survey, $2 \%$ of bronchiolitis discharges were concurrently coded for chronic lung disease. ${ }^{17}$

The incidence of RSV related hospitalisations among the high risk infants in our study was higher than recently reported from the USA and UK. Five per cent of preterm infants under 1 year were rehospitalised for an RSV proven illness compared to $3.2 \%$ in the Kaiser Permanente study. ${ }^{5}$ However, the latter study had underrepresentation of lower socioeconomic groups, where the risk of RSV disease is high. ${ }^{19}$ Similarly, the proportion $(5.6 \%)$ of low birth weight infants rehospitalised with RSV during their first year in our study was twice that $(2.8 \%)$ in the follow up by Nachman et al in New York. ${ }^{20}$ The incidence of RSV related hospitalisation among the preterm infants ( $<36$ weeks gestation) or those under 2 years of age with CLD in our study is broadly similar to the incidence $(10.6 \%)$ in the placebo arm of the IMpact-RSV trial but more than double that in Liverpool. ${ }^{2}$ However, in the 
latter study, RSV was found in only $40 \%$ of infants with bronchiolitis compared to about $60 \%$ in our study. The incidence of RSV related hospitalisation among infants born before 32 weeks in our cohort (10.1\%) again was twice that in London $(4 \%){ }^{6}$

For a sparsely populated county with lower than average rates of deprivation, the rates of RSV disease would have been expected to be lower than in the industrial-urban areas of Liverpool and London. The proportion of high risk infants in our cohort does not appear to be higher than in others. The study periods of the above epidemiological investigations overlap. Changes in the virulence of the RSV strain therefore seem unlikely. We cannot exclude the possibility that the criteria for hospitalisation in our cohort may have been different to others. However, for 1998-99 season, the number of FCEs in children under 2 years from bronchiolitis in our cohort (20.1/1000) was similar to the figure for England (18.9/1000), suggesting that any systematic bias is most unlikely. ${ }^{21}{ }^{22}$ We therefore believe that the rates of RSV related hospitalisations in our cohort reflect a near complete ascertainment of cases.

\section{Serious adverse outcomes}

Our study showed a very low occurrence of serious adverse events, even among high risk infants. The only death occurred in an infant with complex congenital heart disease-a group for whom immunoprophylaxis is currently not indicated. The rates of ICU admission and ventilation were substantially lower than those reported in the Canadian high risk infants $(6.8 \% v 33.6 \%$ for ICU admission and $6.8 \% v$ $15.6 \%$ for ventilation, Shropshire $v$ Canadian $)^{23}$ and in the Kaiser Permanente cohort ( $8.9 \%$ v $18.4 \%$ for ICU admission), ${ }^{5}$ and similar to those found in the palivizumab recipients of the IMpact-RSV study.

\section{Health economic burden of RSV and costs of prophylaxis}

We did not attempt to evaluate the total costs of RSV disease in infancy. In a health care system of finite resources, most new interventions involve shifting of resources so that increased spending in one area is offset by resource saving elsewhere. ${ }^{24}$ Our analysis therefore focused on the direct costs of prophylaxis and hospitalisation from the perspective of a health care provider. Such an approach seems reasonable for an intervention that does not reduce the risk of serious adverse outcomes such as death or need for assisted ventilation. The cost of prophylaxis in our analysis is a conservative estimate since we assumed that all infants weighed less than $3.3 \mathrm{~kg}$, thereby accessing the lowest drug price; furthermore, we did not account for the costs of visits for immunisation, the disposables, and staff costs. Even then our analyses show that direct drug costs to the health authority, following the recommendations of the IMpact-RSV trial or the American Academy of Paediatrics, ${ }^{25}$ would have exceeded the costs of the entire RSV related hospitalisation. Even following the more conservative recommendations of Joffe $^{3}$ and Thomas ${ }^{6}$ would have saved only $1.6 \%$ of the RSV related budget of the health authority, assuming that the prophylaxis would have been successful in averting all the RSV related hospitalisations in these cohorts, but would have added $25 \%$ more costs simply for the drug. Our data confirm the previous suggestions that the RSV immunoprophylaxis strategies are currently too highly priced for the outcomes they avert. ${ }^{4}$ Although their cost effectiveness may be improved through better targeting and a major reduction in their costs, immunoprophylaxis strategies will have only a minor impact on the total clinical and health economic burden of RSV disease in infancy. Reduction of the vast majority of health economic burden of RSV disease in infancy must await development of a safe and effective vaccine.

\section{ACKNOWLEDGEMENTS}

We wish to thank Mr Brian Devine of the Microbiology Department at Royal Shrewsbury hospital, and Mrs Jenny Bennett and Mr Andrew Evans from Shropshire Community and Mental Health trust, as well as a number of consultant paediatricians for their assistance with the study. We are grateful to Dr Ed Hey for his critical review of this manuscript.

\section{Authors' affiliations}

S A Deshpande, Royal Shrewsbury Hospital, Mytton Oak Road, Shrewsbury SY3 8XQ, UK

$\checkmark$ Northern, Shropshire's Community and Mental Health Services NHS Trust, Cross Houses, Shrewsbury SY5 6JN, UK

\section{REFERENCES}

1 Hall CB. Respiratory syncytial virus and parainfluenza virus. N Engl J Med 2001;344:1917-28.

2 The IMpact-RSV Study Group. Palivizumab, a humanised respiratory syncytial virus monoclonal antibody, reduces hospitalisation from respiratory syncytial virus infection in high-risk infants. Pediatrics 1998;102:531-7.

3 Joffe S, Ray GT, Escobar GJ, et al. Cost-effectiveness of respiratory syncytial virus prophylaxis among preterm infants. Pediatrics 1999;104:419-27.

4 Moler FW. RSV immune globulin prophylaxis: is an ounce of prevention worth a pound of cure? Pediatrics 1999;104:559-60.

5 Joffe S, Escobar GJ, Black SB, et al. Rehospitalization for respiratory syncytial virus among premature infants. J Pediatr 1999;104:894-9.

6 Thomas M, Bedford-Russell A, Sharland M. Hospitalisation for RSV infection in ex-preterm infants - implications for use of RSV immune globulin. Arch Dis Child 2000;83:122-7.

7 Clark SJ, Beresford MW, Subhedar NV, et al. Respiratory syncytial virus infection in high risk infants and the potential impact of prophylaxis in a United Kingdom cohort. Arch Dis Child 2000;83:313-16.

8 Martin AJ, Gardner PS, McQuillin J. Epidemiology of respiratory viral infection among paediatric inpatients over a six-year period in north-east England. Lancet 1978;ii: 1035-8.

9 Anon. Report to the Medical Research Council subcommittee on respiratory syncytial virus vaccines. Respiratory syncytial virus infection: admissions to hospital in industrial, urban, and rural areas. BMJ 1978;ii:796-8

10 Simoes EA, Sondheimer HM, Top FHJ, et al. Respiratory syncytial virus immnue globulin for prophylaxis against respiratory syncytial virus disease in infants and children with congenital heart disease. J Pediatr 1998;133:492-9.

11 World Health Organisation. International statistical classification of diseases and related health problems, 10th revision. Geneva: WHO, 1992.

12 Information and Statistics Division. Births in Scotland. Edinburgh: Common Services Agency for NHS Scotland. Available at http:// www.show.scot.nhs.uk/isd/sexual_health/births_in_scottishhosps/Table 10.htm (accessed 11 September 2002)

13 Wren C, Richmond S, Donaldson L. Temporal variability in birth prevalence of cardiiovascular malformations. Heart 2000:83:41-9.

14 Manktelow BN, S DE, Annamali S, et al. Factors affecting the incidence of chronic lung disease of prematurity in 1987, 1992, and 1997. Arch Dis Child Fetal Neonatal Ed 2001;85:F33-5.

15 Greenough A, Alexander J, Burgess S, et al. Home oxygen status and rehospitalisation and primary care requirements of infants with chronic lung disease. Arch Dis Child 2002;86:40-3.

16 Lemons JA, Baver CR, Oh W, et al. Very low birth weight infants of the National Institute of Child Health and Human Development Neonatal Research Network, January 1995 through December 1996. Pediatrics 2001;107:el. Available at: http://www.pediatrics.org/cgi/content/full/ 107/1/el.

17 Shay DK, Holman RC, Newman RD, et al. Bronchiolitis-associated hospitalizations among US Children, 1980-96. JAMA 1999;282:1440-6.

18 Sims DG, Downham MA, McQuillin J, et al. Respiratory syncytial virus infection in north-east England. BMJ 1976;2:1095-8

19 Spencer N, Logan S, Scholey S, et al. Deprivation and bronchiolitis. Arch Dis Child 1996;74:50-2.

20 Nachman SA, Navaie-Waliser M, Qureshi MZ. Rehospitalisation with respiratory syncytial virus after neonatal intensive care unit discharge: a 3-year follow up. Pediatrics 1997;100:e8. Available at: http:// www. pediatrics.org/cgi/content/full/100/6/e8.

21 Department of Health. Hospital in-patient data based on hospital episode statistics (HES). London: DoH, 2001. Available at: http://www.doh.gov.uk/ hes/standard_data/available_tables/primary_diagnosis/tb00398a.pdf (accessed 10 April 2001).

22 Office for National Statistics. Mid-1998 population estimates. Population estimates mid-1998 and mid-1999 based. London: Office for National Statistics, 2000.

23 Navas L, Wang E, de Carvalho V, et al. Improved outcome of respiratory syncytial virus infection in a high-risk hospitalised population of Canadian children. J Pediatr 1992;121:348-54.

24 Briggs $\mathbf{A}$. Economic evaluation and clinical trials: size matters. BMJ 2000;321:1362-3.

25 American Academy of Pediatrics Committee on Infectious Diseases and Committee of Fetus and Newborn. Prevention of respiratory syncytial virus infections: indications for the use of palvizumab and update on the use of RSV. Pediatrics 1998;102:1211-16. 